\title{
Thermal performance of novel frame-integrated unitised curtain wall
}

\author{
Comportamiento térmico de muro cortina modular con marco integrado
}

Belarmino Cordero (Principal and Official Contact Author)

Universidad Politécnica de Madrid, Department of

Construction and Technology in Architecture

Avda. Juan de Herrera, 4. 28040 Madrid.

belarmino.cordero@gmail.com

\author{
Alfonso García-Santos \\ Universidad Politécnica de Madrid \\ alfonso.garciasantos@upm.es
}

\author{
Mauro Overend \\ Cambridge University \\ mo318@cam.ac.uk
}

\section{Resumen}

El diseño de los marcos de aluminio en muros cortina modulares podría ser más eficiente estructuralmente y térmicamente: se podría aprovechar la rigidez de los vidrios para reducir la profundidad estructural y se podrían emplear materiales de menor conductividad térmica que el aluminio. Estas propuestas se han aplicado en el desarrollo de un sistema de muro cortina alternativo en el cual se emplean adhesivos para adherir los montantes al vidrio y conseguir un panel compuesto de gran rigidez. Esto permite reducir la profundidad de los montantes e integralos en el plano del vidrio. La tranmisión térmica se reduce sustituyendo el aluminio por polímeros reforzados de fibra de vidrio. En este artículo se describe el sistema propuesto y se compara su comportamiento térmico con el de un sistema tradicional a través de cálculo analítico y numérico.

Palabras clave: Muro cortina; marco; térmico.

\section{Abstract}

Framing of unitized curtain walls is dimensioned to carry wind load without taking advantage of potential composite contribution of glass. Subsequently, it is unnecessarily deep, occupying valuable space, and protrudes to the inside, causing visual disruption. Moreover, it is generally made of high thermal conductivity metal alloys, contributing to substantial thermal transmission at joints. An innovative frame-integrated unitised curtain wall has been developed that, compared to conventional systems, reduces structural depth significantly, allows an inside flush finish and reduces thermal transmission at joints. The idea is to adhesively bond a Glass Fibre Reinforced Polymer (GFRP) frame to the edge of the Insulated Glass Unit (IGU), thereby achieving low thermal transmittance and composite structural behaviour. The frame is to fit within the glazing cavity depth. This paper provides a description of the proposed system and assesses its thermal transmittance and risk of condensation through comparative analytical and numerical thermal analysis with a conventional system taken as reference.

Keywords: Curtain wall; frame; thermal.

\section{Introduction}

Frames used in conventional unitised curtain wall systems are inherently inefficient, both thermally and structurally. They are generally made of metal alloys with high thermal conductivities, thereby leading to substantial thermal transmission at joints. The thermal inefficiency has only recently come to the fore as the thermal performance of glass units has steadily increased, so that the thermal performance of contemporary curtain walls is governed by the edge-of-glazing and framing regions. Moreover, the frames are structurally inefficient, and therefore much heavier than necessary, as they fail to exploit the potential composite action with the glass panels. This structural inefficiency also leads to space planning problems and aesthetic weaknesses as the frames occupy valuable space, and protrude into buildings, causing visual disruption.

\section{Objectives}

A novel frame-integrated unitised curtain wall is being developed to reduce thermal transmission at joints, reduce structural depth significantly and allow an inside flush finish. The proposed system will consist of a Glass Fibre Reinforced Polymer (GFRP) frame adhesively bonded along the perimeter of an Insulated Glass Unit (IGU). The removal of the metallic frame will reduce the thermal transmittance and the use of the structural adhesive will mobilise the campsite action between the glass and the GFRP frame. Furthermore the frame will fit within the cavity of the IGU.

Several different aspects of the design such as thermal and structural performance have been analysed as part of a broad multidisciplinary research project. This paper focusses on thermal transmittance and risk of condensation through comparative analytical and numerical thermal analysis with a conventional system taken as reference.

\section{State of the art}

\section{Unitised curtain wall systems}

Unitised curtain wall systems consist of factory-assembled cladding panels which can be fitted to the building via pre-fixed brackets along the edge of the floor slab. They are universally used for high-rise buildings because the pre-fabricated assembly of units ensures high quality and allows fast installation without external access. Furthermore, they can accommodate considerable building movement.

Insulating glazing units 
An IGU is an assembly consisting of at least two panes of glass, separated by one or more spacers, hermetically sealed along the periphery, mechanically stable and durable (BS EN 1279-1, 2004). Compared to single glazing, the use of double glazing primarily reduces energy transmission into and out of a building, but it can also reduce internal condensation, improve thermal comfort and reduce noise transmission. The design and manufacturing of the sealing along the edge of the unit determines its durability, the extent of thermal bridging through the edge and the proportion of composite structural action between the spacer and the glass panes. To ensure durability, the sealing has to provide low moisture vapour transmission, guarantee material compatibility, have good resistance to water, temperature changes and ultraviolet radiation and be sufficiently flexible to accommodate differential thermal expansion between the glass panes and the spacer and bowing caused by pressure variations (CWCT, 2010).

\section{Composite structural action}

The concept of bonding the glass panels to the framing members is not in itself new. In fact one form of unitised curtain wall system, known as structural silicone glazing, uses low stiffness silicone adhesives with a bond line thickness $\geq 6 \mathrm{~mm}$. This produces a relatively flexible joint that accommodates the differential thermal expansion between the glass panels and the metal framing members. The disadvantage of this flexible joint is that it is too compliant and it therefore mobilises an insignificant amount of composite structural action between the panes and the framing members. The novelty of the composite unitised system discussed in this paper is that the façade framing members consist of GFRP pultrusions that have a coefficient of thermal expansion similar to that of glass, This makes it possible to use stiffer adhesives with thinner bond lines thereby generating significant composite structural action between glass panels and the frames.

There is a paucity of research on composite glass-frame systems where reinforced glass panels are subjected to flexure about their minor axis. Wurm (2007) developed three prototypes of GFRP-glass composite units with two plates of glass adhesively bonded to GFRP bars arranged in parallel in the glazing cavity. Petersen (2013) developed a window system based on a GFRP frame which is bonded to an IGU achieving composite structural behaviour and low thermal transmittance. Seele (2010) proposed a self-supporting IGU with a thermally broken spacer bar that is structurally bonded to the glass panes. These systems, however, are not unitized and do not have the level of prefabrication that is required for high rise façades.

\section{Thermal transmission}

The performance of ten different spacer bars in Insulated Glass Units (IGUs) mounted on frames of four different materials was assessed by Elmahdy (2003), from the National Research Council of Canada, to determine the factors that affect the thermal transmission at joints. This study concluded that the overall U-value of a window assembly is dependent on the type of spacer bar, frame material (and design), and glazing, and is particularly affected by the thermal properties of the frame material. For example, for the same conventional spacer, the Uvalue of the assembly varied by $20 \%$ depending on the frame and ,for the same wooden frame, the U-value of the assembly varied by $15 \%$ depending on the spacer. Research carried out at the University of Cambridge shows that the improvements achieved by technological developments of high performance glazing are such that the thermal performance of curtain wall systems is currently governed by the framing (Jin et al, 2009). The additional benefit of the GFRP pultrusions is their low thermal conductivity which reduces unwanted heat transfer and the risk of condensation.

Muñoz and Bobadilla (2012) undertook the task of developing a range of thermally efficient façade systems through an process that involved $\mathrm{U}$-value and condensation risk assessment calculations. The performance of the initial design was assessed and then modifications were proposed in an iterative process. This study demonstrated the importance of addressing thermal bridges as well as overall U-values to properly characterize a façade system.

Curtain walls often contain different kinds of materials, joined in different ways, and can exhibit numerous variations of geometrical shape. With such a complex structure, the likelihood of producing thermal bridges across the curtain wall envelope is quite high. For this reason, standard procedures have been established to calculate the thermal transmittance of curtain wall structures. BS EN 12631 (2012) and ANSI/NFRC 100 (2014) are the reference standards in Europe and America respectively. They both describe overall system U-value calculation methods based on area weighting the $U$-values of the different components. Using validated computer software is industry common practice to obtain specific U-values for bespoke systems.

\section{Proposed system}

The proposed composite unitised system consists of a GFRP frame adhesively bonded along the perimeter of an IGU as shown in figure 1 . A conventional system is sketched on figure 2 for comparison. The removal of the metallic frame reduces the thermal transmittance and the use of structural adhesive mobilises the campsite action between the glass and the FRP frame. Furthermore the frame fits within the cavity of the IGU.

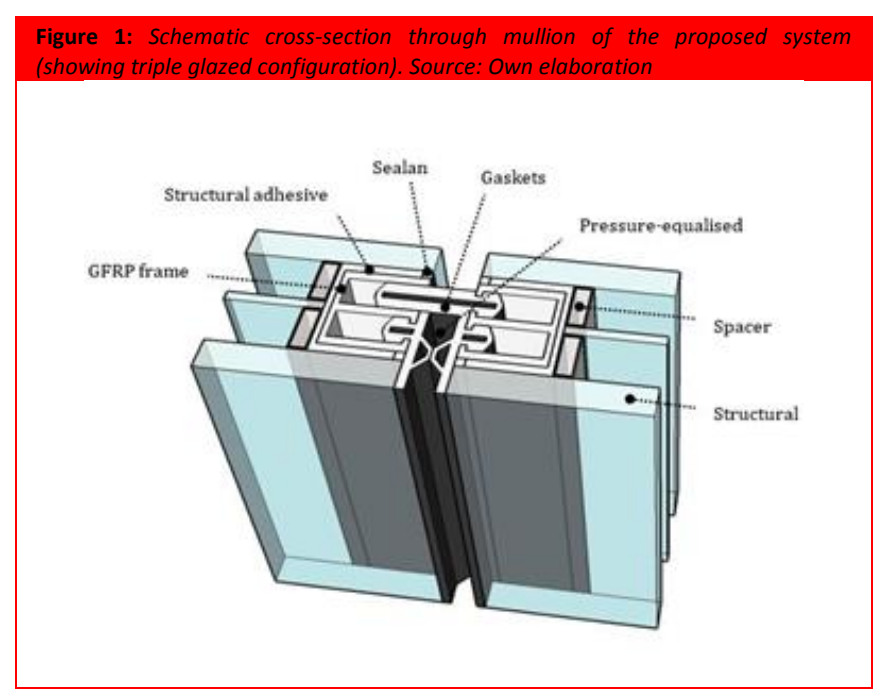




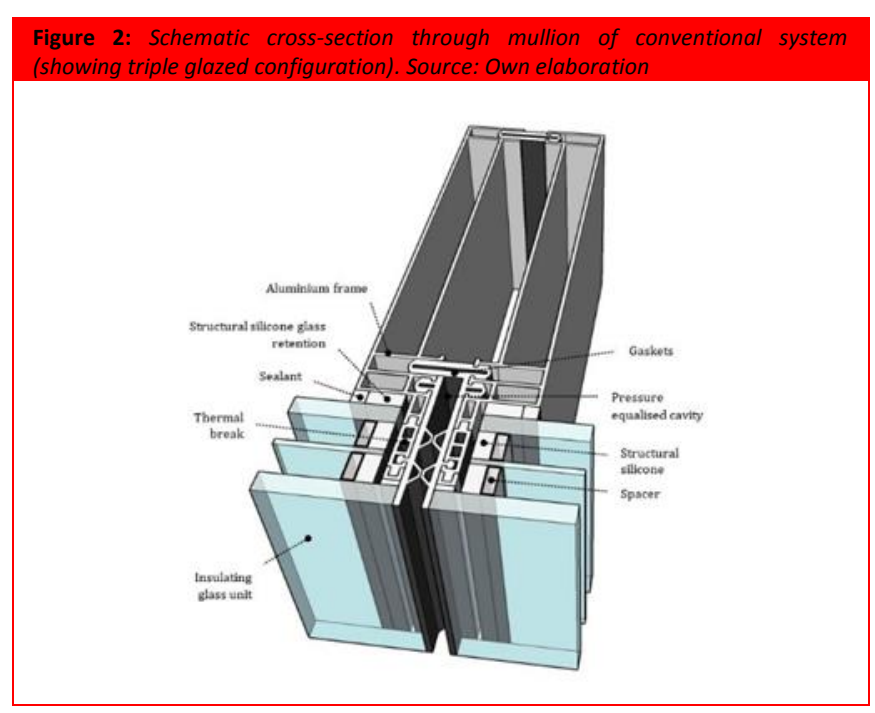

\section{Calculation Methodology}

Figure 3 illustrates the complete process map. On the left hand side, the input parameters that had to be defined: environmental conditions, materials and geometry. On the right hand side, the output data: U-values and risk of condensation. The details have been drawn in Autocad http://www.autodesk.co.uk/products/autocad/overview. The U-value calculations have been carried out following ANSI/NFRC 100 (2014). State-of-the-art computer software developed at Lawrence Berkeley National Laboratory has been used: WINDOW 6.3.9.0 http://windows.lbl.gov/software/window/window.html to model the glazing build-up and calculate the U-value at the centre-of-glazing. The glazing has been then imported into THERM 6.3.19.0 http://windows.lbl.gov/software/therm/therm.html to be modelled with the rest of components. This software has been selected because it has been especially tailored to model products for NFRC certification. It provides flexibility to model bespoke details by allowing to import CAD drawings. It is a robust software developed by a prestigious university and funded by the United States Government. It is available for free on line and widely used in industry.

For condensation analysis the same procedure has been followed except for the environmental conditions, for which typical conditions would normally be assumed based on the climate at the building location and the use of the building. In this case, $-5 \stackrel{\circ}{\circ}$ have been assumed as external temperature while typical office conditions of $21 \stackrel{\circ}{\circ}$ and $40 \%$ have been assumed as internal temperature and internal relative humidity.Condensation occurs on a surface if the surface temperature is below the dew-point temperature. A temperature profile has been generated through each crosssection analysed to obtain the inside surface temperature. Based on the assumed internal temperature of 21 ㅇ $C$ and relative humidity of $40 \%$, a dew-point Temperature of $279.9 \mathrm{~K}$

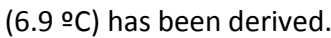

The U-value of the glazing edge and the frames has been obtained for each of the main cross-sections. The overall façade $\mathrm{U}$-value has been calculated by area weighting these U-values in accordance with equation 1 taken from THERM 6.3 / WINDOW
6.3 National Fenestration Rating Council Simulation Manual (Lawrence Berkeley National Laboratory, 2011).

The U-value of the glazing edge and the frames has been obtained for each of the main cross-sections. The overall façade $\mathrm{U}$-value has been calculated by area weighting these U-values in accordance with equation 1 taken from THERM 6.3 / WINDOW 6.3 National Fenestration Rating Council Simulation Manual (Lawrence Berkeley National Laboratory, 2011).

$\mathrm{U}_{\mathrm{t}}=\frac{\Sigma\left(\mathrm{U}_{\mathrm{f}} * \mathrm{~A}_{\mathrm{f}}\right)+\Sigma\left(\mathrm{U}_{\mathrm{e}} * \mathrm{~A}_{\mathrm{e}}\right)+\Sigma\left(\mathrm{U}_{\mathrm{c}} * \mathrm{~A}_{\mathrm{c}}\right)}{\mathrm{At}}$

Where:

$\mathrm{Ut}=$ Total U-value $[\mathrm{W} / \mathrm{m} 2 \mathrm{~K}]$

At $=$ Total area $[\mathrm{m} 2]$

$\mathrm{Uf}=$ Frame $\mathrm{U}$-value $[\mathrm{W} / \mathrm{m} 2 \mathrm{~K}]$

Af $=$ Frame area $[\mathrm{m} 2]$

Ue = Edge-of-glazing U-value $[\mathrm{W} / \mathrm{m} 2 \mathrm{~K}]$

$\mathrm{Ae}=$ Edge-of-glazing area [m2]

$\mathrm{Uc}=$ Centre-of-glazing U-value $[\mathrm{W} / \mathrm{m} 2 \mathrm{~K}]$

$A c=$ Centre-of-glazing area $[\mathrm{m} 2]$

Assumptions regarding elevation dimensions, material properties and environmental conditions are identical for both systems compared. Figure 4 represents a schematic elevation of a curtain wall unit with the dimensions that have been considered for the calculation of the frame, the edge-of-glazing and the centre-of-glazing areas according to the proposed design and NFRC standards.

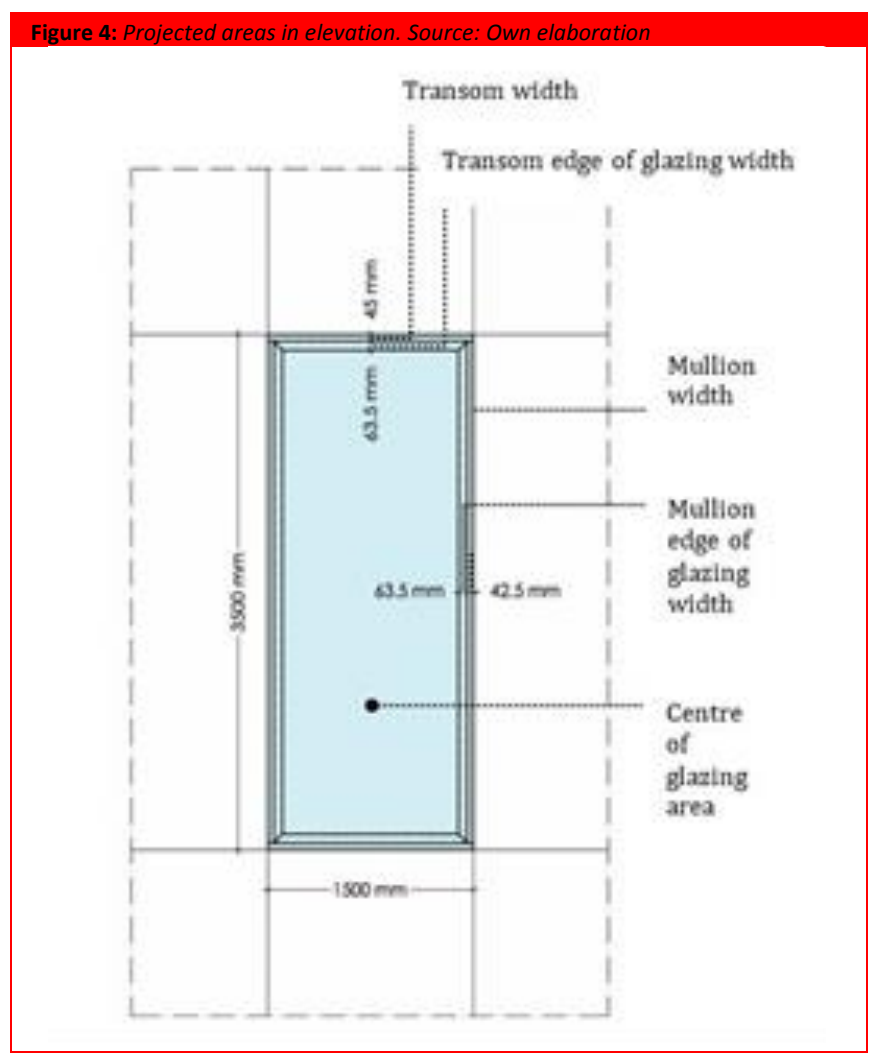



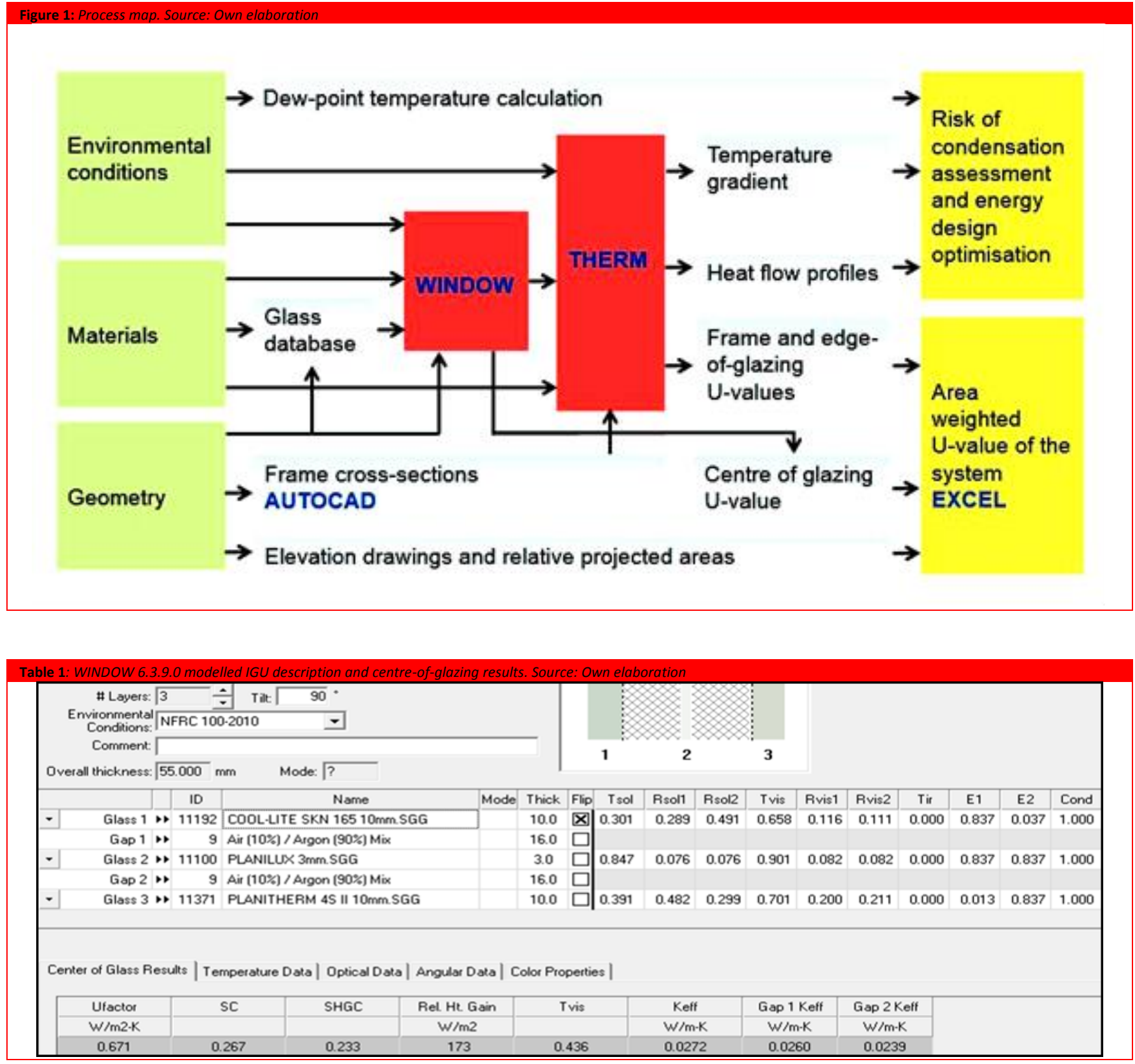

\begin{tabular}{|c|c|c|c|}
\hline Material & Component & $\begin{array}{l}\text { Thermal Conductivity } \\
\lambda[\mathrm{W} / \mathrm{mK}]\end{array}$ & $\begin{array}{l}\text { Emissivity } \\
\varepsilon[-]\end{array}$ \\
\hline Aluminium alloy (anodised) & Frame & 160 & 0.90 \\
\hline Butyl rubber & Spacer primary seal & 0.17 & 0.90 \\
\hline \multicolumn{4}{|c|}{ Cavities modelled as Frame cavity NFRC 100 or Frame cavity Slightly Ventilated NFRC 100} \\
\hline Ethylene propylene diene monomer & Gasket & 0.25 & 0.90 \\
\hline Fibreglass & Frame & 0.30 & 0.90 \\
\hline Glass (soda lime) & Stepped glass & 1.0 & 0.84 \\
\hline \multicolumn{4}{|c|}{ IGU imported from WINDOW 6.3.9.0. with $0.67 \mathrm{~W} / \mathrm{m} 2 \mathrm{~K}$ centre-of-glazing U-value } \\
\hline Polyamide (nylon) & Thermal break & 0.25 & 0.90 \\
\hline Silica gel (loose fill) & Spacer desiccant & 0.13 & 0.90 \\
\hline Silicone & Adhesive, sealant & 0.35 & 0.90 \\
\hline Stainless steel & Vapour barrier foil & 15 & 0.20 \\
\hline Structural adhesive & Structural adhesive & 0.4 & 0.90 \\
\hline Styrol acril nitril copolymer & Spacer main body & 0.16 & 0.90 \\
\hline
\end{tabular}




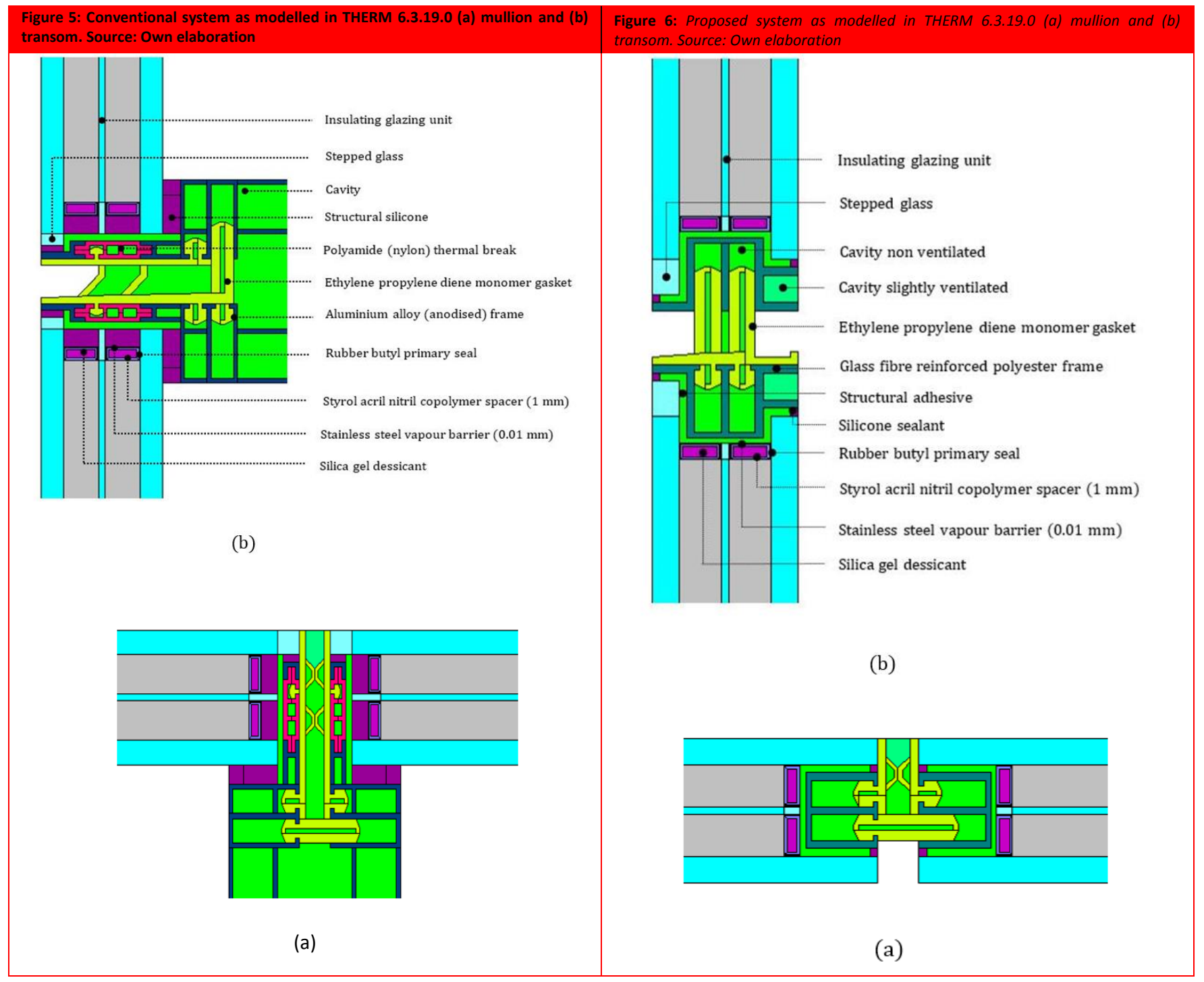

The IGU has been modelled as triple glazing with $16 \mathrm{~mm}$ Argonfilled cavities and high performance coatings. Table 1 describes the precise build up based on products which are available in industry. The centre-of-glazing $\mathrm{U}$-value result is $0.67 \mathrm{~W} / \mathrm{m} 2 \mathrm{~K}$.

Figure 5 and 6 represent the main cross sections of the conventional system and the proposed system respectively as modelled indicating the materials. It should be noted that, being a $2 \mathrm{D}$ analysis, there are elements that are not modelled such as weep holes, setting blocks, corner keys, etc. These elements are usually disregarded in U-value calculations as their influence is negligible. Each material has been modelled with a determined thermal conductivity $\lambda[\mathrm{W} / \mathrm{mK}]$ and emissivity $\varepsilon$ as shown in table 2. A thermal conductivity of $0.4 \mathrm{~W} / \mathrm{mK}$ has been assigned to a standard structural adhesive. The design of the spacers is based on the information provided by a recognised warm-edge spacer manufacturer (Swissspacer, 2008) with a main body of composite plastic and a stainless steel foil that functions as vapour barrier.The conditions assumed are NFRC standardized environmental conditions for $\mathrm{U}$-factor calculations for product ratings listed in table 3 .

\section{Results and discussion}

Heat flow and U-values for the conventional and proposed systems are described in tables 4 and 5 . Against the conventional system, the proposed system achieves a reduction of the heat flow through the frame area of $45 \%$ while the heat flow through the edge of glazing area is increased by $33 \%$. The total area-weighted $\mathrm{U}$-value of the system is reduced by $10 \%$.

Heat flow profiles of representative transom and mullion sections for conventional and proposed systems are illustrated in figure 7. The heat flow across the conventional system is unevenly distributed with the aluminium frame concentrating large peak values reaching over $2000 \mathrm{~W} / \mathrm{m} 2$. Where the aluminium frame is thermally broken, the heat flow is bypassed through the edge of the IGU, mainly through the steel vapour barrier and the structural silicone. The heat flow across the proposed system is more evenly distributed with highest values just over $300 \mathrm{~W} / \mathrm{m} 2$ located at the stainless steel vapour barrier, the GFRP frame and the structural adhesive. While the conventional system concentrates the heat flow at the frame area, the proposed system distributes the flow between the frame and the edge of glazing areas. 
Temperature profiles of representative transom and mullion sections for conventional and proposed systems are illustrated in figure 8. Eliminating the frame protrusions to the inside in the proposed system implies that less surface is exposed to the inside. Moreover, the distance between the external and internal surfaces is reduced provoking a steeper temperature gradient. These facts result in lower inside surface temperatures for the proposed system than for the conventional system. For the assumed environmental conditions, the lowest surface temperature is 10.2 o $\mathrm{C}$ and is located at the transom gasket. This temperature is still above the calculated dew-point temperature of $6.9 \stackrel{\circ}{\circ}$ so there is no risk of condensation.

\begin{tabular}{|c|c|}
\hline Variable & Assumed values \\
\hline Outside Temperature & $-18^{\circ} \mathrm{C}$ \\
\hline Inside Temperature & $21^{\circ} \mathrm{C}$ \\
\hline Wind Speed & $5.5 \mathrm{~m} / \mathrm{s}$ \\
\hline Wind Direction & Windward \\
\hline Direct Solar & $0 \mathrm{~W} / \mathrm{m} 2$ \\
\hline Sky Temperature & $-18^{\circ} \mathrm{C}$ \\
\hline Sky Emissivity & 1.00 \\
\hline \multicolumn{2}{|c|}{$\begin{array}{l}\text { * The conditions assumed for the condensation risk assessment } \\
\text { are identical except for the Outside Temperature, which is }-5 \stackrel{\circ}{\circ} \mathrm{C}\end{array}$} \\
\hline
\end{tabular}
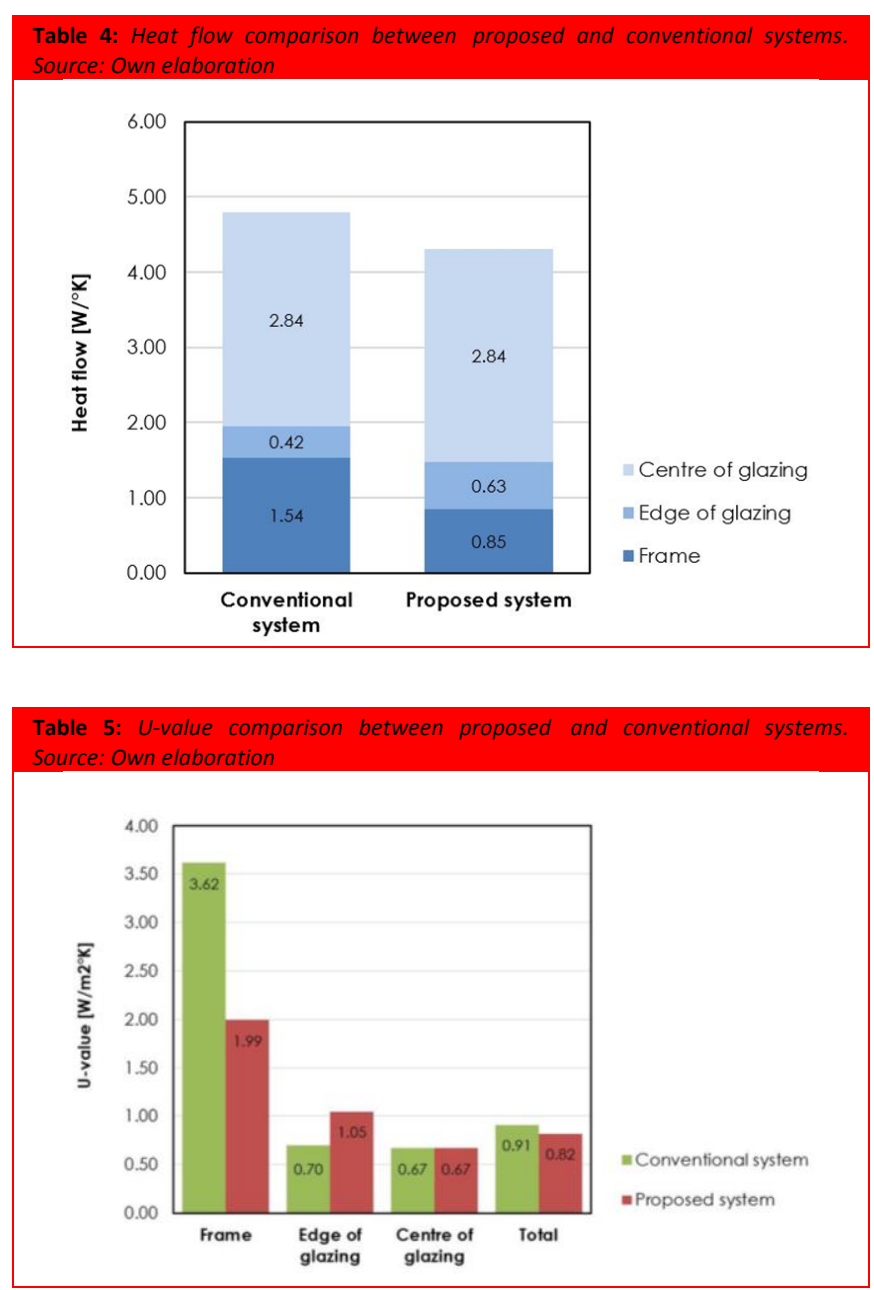

\section{Conclusion}

Against the conventional system, the proposed system achieves a total area-weighted U-value reduction of $10 \%$. This is achieved due to substantial improvement at the frame area and despite substantial worsening at the edge of glazing area. The improvement provided by the proposed system against the conventional system would be more pronounced if the proportion of frame area against glazing area was higher, which is generally the case with most curtain wall units comprising intermediate frames. Moreover, as the thermal performance of glazing improves in the future, the relevance of the performance of the frame will increase further.

The heat flow across the conventional system is unevenly distributed with the aluminium frame concentrating large peak values. Where the aluminium frame is thermally broken, the heat flow is bypassed through the edge of the IGU, mainly through the steel vapour barrier and the structural silicone. The heat flow across the proposed system is more evenly distributed with moderate peak values located at the stainless steel vapour barrier, the GFRP frame and the structural adhesive. While the conventional system concentrates the heat flow at the frame area, the proposed system distributes the flow between the frame and the edge of glazing areas.

The proposed system presents lower temperatures in the inside surfaces than the conventional system. This is due to the fact that the proposed system is narrower, provoking a steeper temperature gradient. Moreover, by eliminating the frame protrusions to the inside, the heat transfer surface of the frame is reduced. Nevertheless, the temperature is still above the calculated dew-point temperature so there is no risk of condensation.

While the performance of the conventional system is close to its full potential, the design of the proposed system is at a schematic stage and there is still scope for optimization. The design could be improved by reducing the thickness of the GFRP frame web and altering the composition of the adhesive and GFRP to reduce its thermal conductivity. Integrating the frame with the spacers could also be contemplated. 


\section{References}

ANSI/NFRC 100 (2014). Procedure for Determining Fenestration Product U-factors. American National Standards Institute / National Fenestration Rating Council: Greenbelt, United States

BS EN 1279-1 (2004). Glass in building - Insulating glass units. British Standards Institution: London, United Kingdom

BS EN 13947 (2006). Thermal performance of curtain walling Calculation of thermal transmittance. British Standards Institution: London, United Kingdom

CWCT (2010). Technical note 62 - Specification of insulating glass units. University of Bath: Bath, United Kingdom

Elmahdy, A. H. (2003). Effects of improved spacer bar design on window performance. National Research Council of Canada. IRC Construction Technology Update, 58, Ottawa: National Research Council of Canada.

Jin, Q. et al (2009). The performance and optimization of a novel facade panel for energy efficiency building. In: CISBAT Conference, Lausanne.

Lawrence Berkeley National Laboratory (2011) THERM 6.3 / WINDOW 6.3 National Fenestration Rating Council Simulation Manual: Berkeley, United States

Muñoz, C., Bobadilla, A. (2012). Simulación y evaluación de puentes térmicos: Soluciones constructivas típicas aprobadas por la Norma Térmica para elementos verticales en estructura de madera y metálicos en la Zona 4 Simulaciones con Therm y Usai y evaluación con Método de Cámara Térmica. Revista de la Construcción, 11(2), 92-111.

NFRC 100 (1997). Procedures for Determining Fenestration Product Ufactors. Equation 4. National Fenestration Rating Council: Greenbelt, United States

Petersen, L. (2013). Building façade structure with joined pultruded elements. US Patent 8,402,705 B2: United States

Seele, G. (2010). Insulating glass unit. US Patent 2010/0011703: Munich, Germany

Swisspacer (2008). Datasheet Swisspacer V [online]. Available from: http://www.swisspacer.com/en/sites/default/files/products/docu ments/Swisspacer\%20V\%20datasheet.pdf [Accessed 22 March 2014]

Wurm, J. (2007). Glass structures: design and construction of selfsupporting skins, Basel: Birkhäuser, ISBN: 978-3-7643-7608-6 / 978-3-7643-8317-6. 


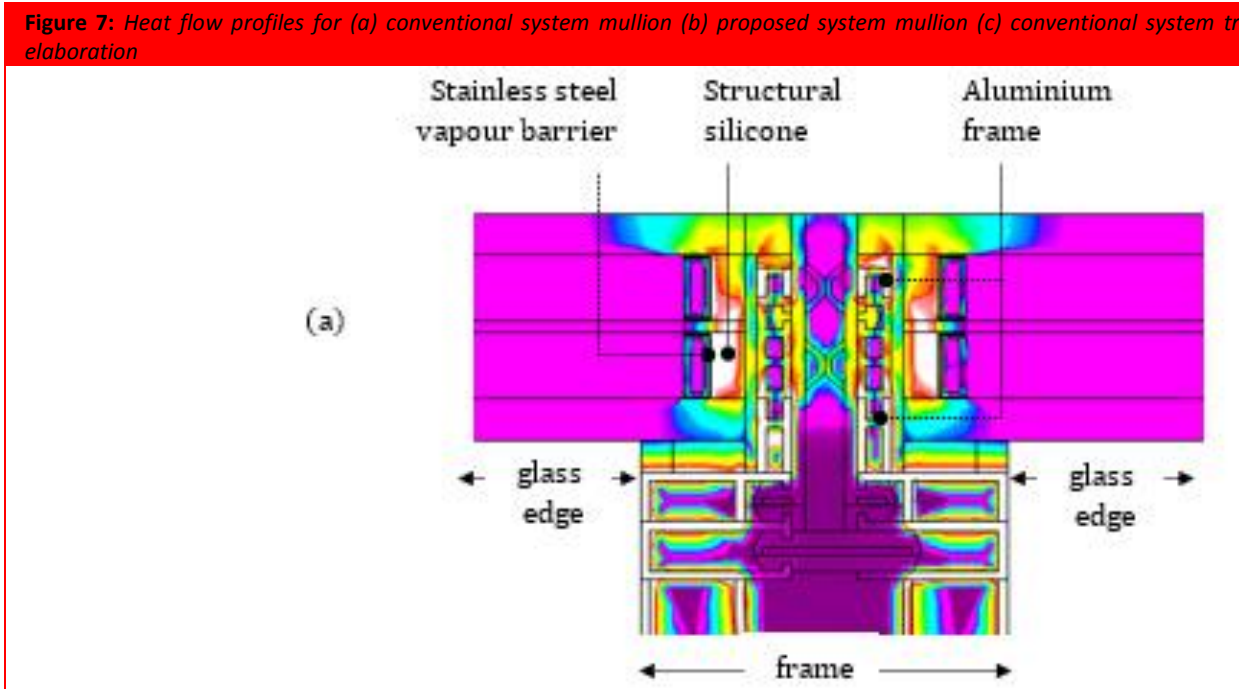

Stainless steel GFRP frame and

vapour barrier structural adhesive

(b)

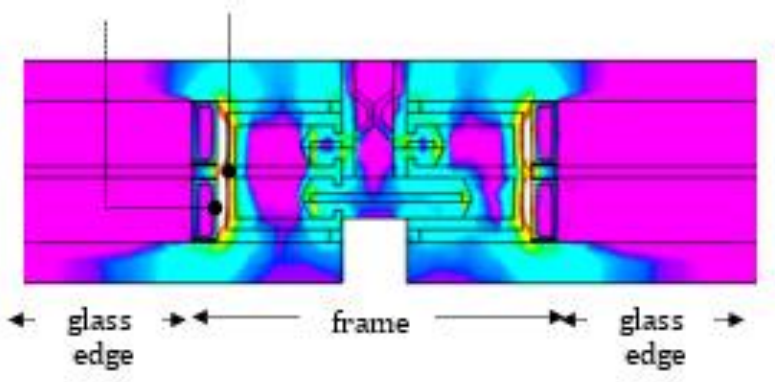

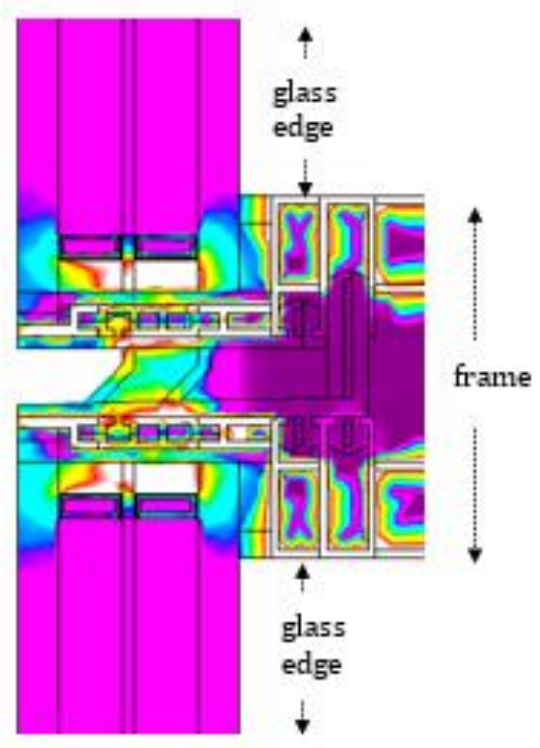

(c)

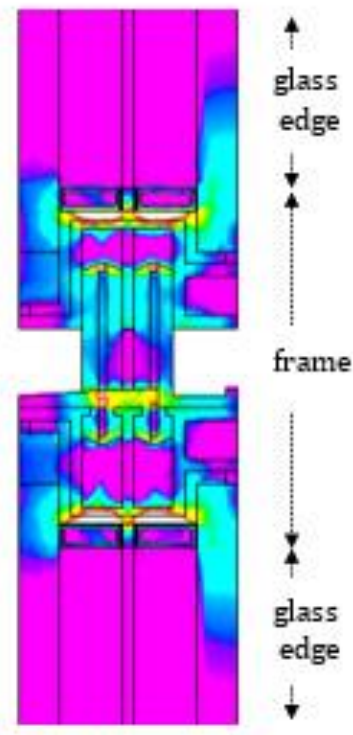

(d) 
Figure 8: Temperature profiles and location of areas with minimum inside surface temperature for (a) conventional system mullion (b) proposed system mullion (c) conventional system transom (d) proposed system transom. Source: Own elaboration

(a)

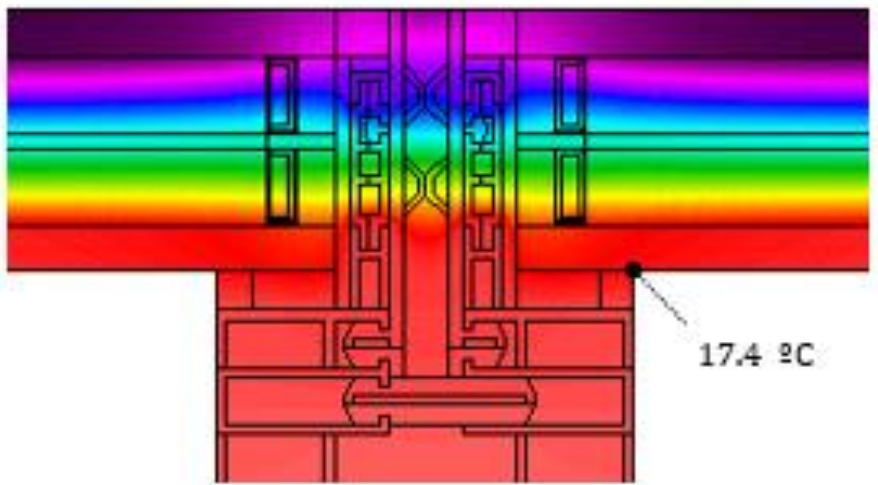

(b)

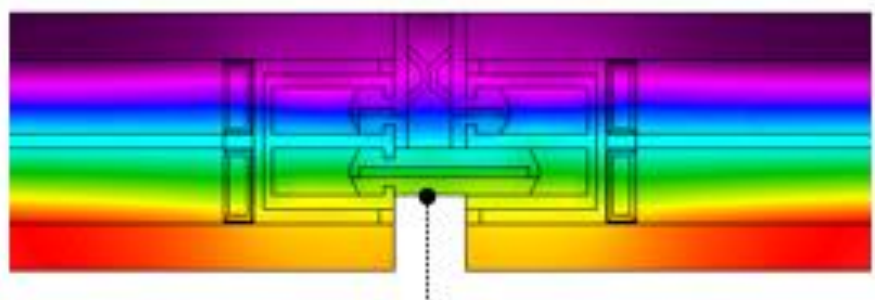

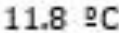

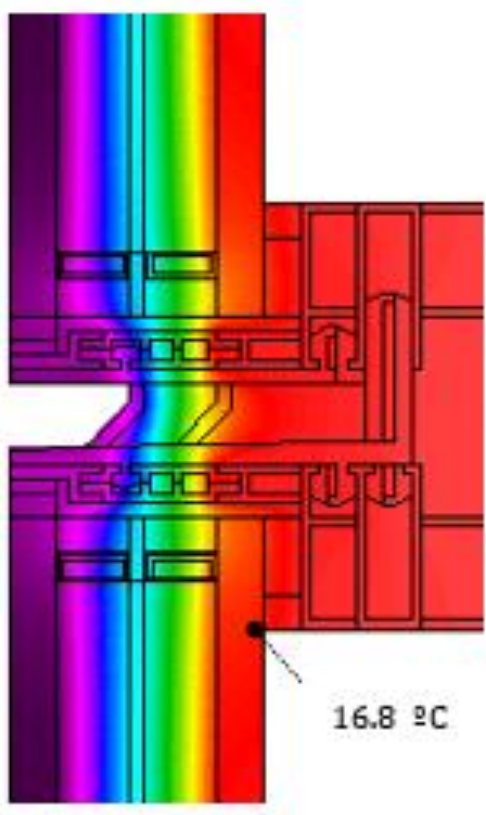

(c)

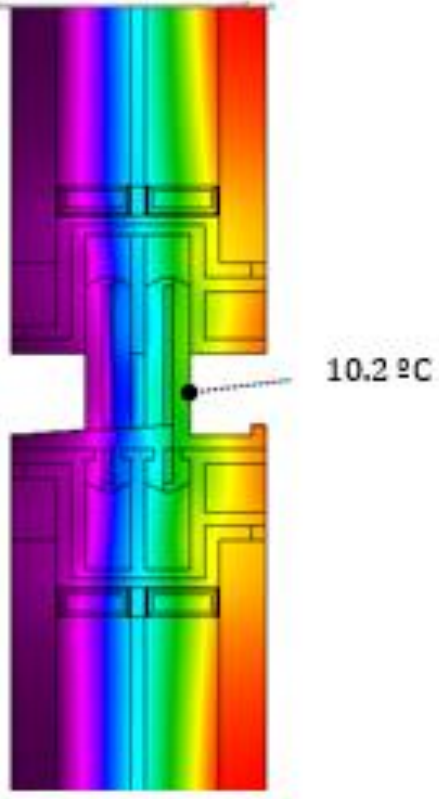

(d)

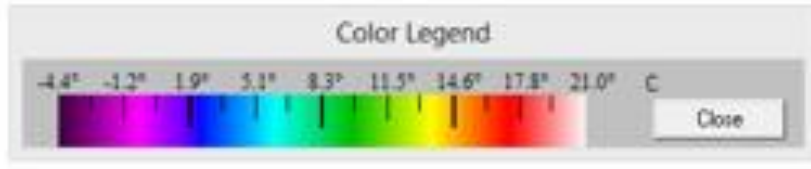

